Я.М. Вахрушев', Н.А. Хохлачева*1, П.С. Михеева²,

\title{
Е.В. Сучкова'
}

1 - ФГБОУ ВО Ижевская государственная медицинская академия МЗ РФ, Ижевск, Россия

² БУз УР ГКБ № 8 им. И.Б. Однопозова МЗ УР, Ижевск, Россия

\section{МЕХАНИЗМЫ НАРУШЕНИЙ \\ МОТОРНО-ЭВАКУАТОРНОЙ ФУНКЦИИ ЖЕАЧНОГО ПУЗЫРЯ И ИХ ЗНАЧЕНИЕ В РАЗВИТИИ ХО Е ИИТИАЗА}

\author{
Ya.M. Vakhrushev ${ }^{1}$, N.A. Khokhlacheva*1, P.S. Mikheeva², \\ E.V. Suchkova ${ }^{1}$ \\ 1_ Izhevsk State Medical Academy, Izhevsk, Russia \\ ${ }^{2}$ - City Clinical Hospital № 8 name I.B. Odnopozov , Izhevsk, Russia
}

\section{THE MECHANISMS OF THE DISORDERS OF MOTOR-EVACUATION FUNCTION OF GALL BLADDER AND THEIR IMPORTANCE IN THE DEVELOPMENT OF CHOLELITHIASIS}

\begin{abstract}
Резюме
Цель исследования - изучение роли гастрина в нарушении моторно-эвакуаторной функции желчного пузыря и биохимических свойств желчи при желчекаменной болезни. Материал и методы. Обследованы 230 пациентов с патологией билиарной системы. В верификации диагноза, помимо общеклинических данных, использованы результаты ультразвукового исследования гепатобилиарной системы. Для изучения функционального состояния желчного пузыря использованы холецистометрия и динамическая гепатобилисцинтиграфия. При различных вариантах нарушения моторно-эакуаторной функции желчного пузыря проведено изучение биохимических свойств желчи (холестерин, желчные кислоты, холато-холестериновый коэффициент), полученной в результате многофракционного дуоденального зондирования. Уровень гастроинтестинального гормона гастрина в периферической крови определялся иммуноферментным методом. Результаты. При ультразвуковом исследовании у 78\% пациентов обнаружены признаки билиарного сладжа. В 75,4\% случаев при микроскопии желчи обнаружены кристаллы холестерина и билирубината кальция. Изучение биохимического состава выявило повышение уровня холестерина, снижение уровня желчных кислот и холато-холестеринового коэффициента в порциях В и С желчи. Нарушения моторно-эвакуаторной функции желчного пузыря, являющиеся одним из патогенетических факторов холелитиаза, выявлены у $72 \%$ обследованных пациентов. У больных уровень гастрина был снижен, причем в большей степени - при дисфункции желчного пузыря по гипокинетическому типу. Методом корреляционного анализа установлена значимая роль гастрина в изменении функционального состояния желчного пузыря и, тем самым, в формировании литогенной желчи. Заключение. Исследования показателей моторной функции желчного пузыря и биохимических свойств желчи с одной стороны и уровня гастроинтестинального гормона гастрина с другой позволили показать важную роль гипогастринемии в формировании литогенной желчи путем подавления опорожнения желчного пузыря.

Ключевые слова: желчный пузырь, моторно-эвакуаторная функция, литогенные свойства желчи, холелитиаз, гастрин

Для цитирования: Вахрушев Я.М., Хохлачева Н.А., Михеева П.С., СУчкова Е.В. МЕХАНИЗМЫ НАРУШЕНИЙ МОТОРНО-ЭВАКУАТОРНОЙ ФУНКЦИИ ЖЕЛЧНОГО ПУЗЫРЯ И ИХ ЗНАЧЕНИЕ В РАЗВИТИИ ХОЛЕЛИТИАЗА. АРХИВъ вНУТРЕНнЕЙ медИцинЫ. 2018; 8(1): 53-58. DOI: 10.20514/2226-6704-2018-8-1-53-58
\end{abstract}

\footnotetext{
Abstract

The aim of the study was to study the role of gastrin in disturbing the motor-evacuator function of the gallbladder and the biochemical properties of bile in cholelithiasis. Material and methods. 230 patients with pathology of the biliary system were examined. In verification of the diagnosis,
}

*Контакты/Contacts. E-mail: stoxel@yandex.ru 
in addition to general clinical data, the results of ultrasound investigation of the hepatobiliary system were used. Cholecystometry and dynamic hepatobiliary scintigraphy were used to study the functional state of the gallbladder. In various variants of the motor-ejaculatory function of the gallbladder, a study was made of the biochemical properties of bile (cholesterol, bile acids, cholate-cholesterol coefficient) obtained as a result of multifraction duodenal sounding. The level of the gastrointestinal hormone gastrin in the peripheral blood was determined by the enzyme immunoassay. Results. With ultrasound, $78 \%$ of the patients in the US are diagnosed with signs of biliary sludge. In $75.4 \%$ of cases with microscopy of the same species, crystals of cholesterol and calcium bilirubin were detected. The study of the biochemical composition revealed an increase in cholesterol, a decrease in bile acids and a cholate-cholesterol coefficient in portions B and C of bile. Disturbances of motorevacuation function of the gallbladder, which are one of the pathogenetic factors of cholelithiasis, were detected in $72 \%$ of the patients examined. In patients, the level of gastrin was reduced, and to a greater extent - with gallbladder hypomotorism. The significant role of gastrin in changing the functional state of the gallbladder and, therefore, in the formation of lithogenic bile is established by the method of correlation analysis. The conclusion. Investigations of the parameters of the motor function of the HP and the biochemical properties of bile on the one hand and the level of the gastrointestinal hormone gastrin on the other have shown the important role of hypogastrinemia in the formation of lithogenic bile by suppressing the emptying of the HP.

Key words: gall bladder, motor-evacuator function, lithogenic properties of bile, cholelithiasis, gastrin

For citation: Vakhrushev Ya.M., Khokhlacheva N.A., Mikheeva P.S., Suchkova E.V. THE MECHANISMS OF THE DISORDERS OF MOTOR-EVACUATION FUNCTION OF GALL BLADDER AND THEIR IMPORTANCE IN THE DEVELOPMENT OF CHOLELITHIASIS. The Russian Archives of Internal Medicine. 2018; 8(1): 53-58. [In Russian]. DOI: 10.20514/2226-6704-2018-8-1-53-58

DOI: $10.20514 / 2226-6704-2018-8-1-53-58$

ЖКБ - желчекаменная болезнь, ЖП - желчный пузырь, ЖКВ - желчные кислоты порции В желчи, ЖКС - желчные кислоты порции С желчи, ХСВ - холестерин порции В желчи,ХСС - холестерин порции С желчи, ХХКВ - холато-холестериновый коэффициент порции В желчи, ХХКС- холато-холестериновый коэффициент порции С желчи

\section{Введение}

Одной из актуальнейших проблем клинической медицины является желчекаменная болезнь (ЖКБ) [1, $2,3,5,6]$, имеющая высокую и год от года возрастающую распространенность, выраженное негативное влияние на социальную активность и качество жизни. По данным статистики, в последние десятилетия увеличение заболеваемости ЖКБ является устойчивым трендом, если сегодня она зарегистрирована более чем у 10\% населения [2, 3, 6, 7], то, при сохранении современных темпов роста заболеваемости, к 2050 году ЖКБ будет страдать 20\% населения планеты [8].

Формирование конкрементов в желчном пузыре (ЖП) - Алительный многостадийный процесс. Ао настоящего времени ведутся дискуссии о патогенетических факторах холелитиаза. Необходимым условием желчного камнеобразования, помимо формирования литогенной желчи [9, 10], является нарушение двигательной функции ЖП $[11,12]$. Исследованиями в эксперименте на животных показана причастность гастроинтестинальных гормонов к процессам желчеобразования и желчевыделения [13]. Однако механизмы изменений метаболизма желчи и сократительной способности ЖП изучены недостаточно.

\section{Цель исследования}

Изучить роль гастрина в нарушении моторно-эвакуаторной функции ЖП и биохимических свойств желчи при ЖКБ.

\section{Материал и методы}

Обследовано 230 пациентов с I стадией ЖКБ (классификация ЦНИИГ, 2001) [4], развившейся на фоне гепатобилиарной патологии (функциональные расстройства желчевыводящей системы, хронический некалькулезный холецистит, стеатогепатиты и стеатогепатозы алиментарной этиологии). Средний возраст пациентов составил 47+6 лет, среди них было 113 мужчин и 117 женщин. Обследование больных осуществлялось при обязательном подписании ими информированного добровольного согласия согласно приказа № 390н Минздравсоцразвития РФ от 23 апреля 2012 г (зарегистрирован Минюстом РФ 5 мая 2012 г. под № 24082). Аанное исследование было одобрено этическим комитетом ФГБОУ ВО Ижевская государственная медицинская академия. Объем обследования был обоснован статистически по частоте выборки с применением формулы л. Закса.

В верификации диагноза, наряду с анамнестическими и общеклиническими данными, учитывались результаты ультразвукового исследования (УЗИ) гепатобилиарной системы на аппарате S- $\mathrm{AH}-500$ (с использованием двух стандартных датчиков (линейного и конвексивного) с частотой 3,5 МГц). Аля оценки функционального состояния ЖП использованы данные холецистометрии и динамической гепатобилисцинтиграфии (АГБСГ). Холецистометрия осуществлялась по общепринятой методике, заключающейся в измерении при УЗИ объема ЖП до и после желчегонного завтрака с 10-минутным интервалом (в течение 1,5 часов). В качестве желчегонного завтрака использовали 2 сырых яичных желтка. 
Объем ЖП рассчитывали по формуле $\mathrm{V}=3,14 \mathrm{dH}$, где d - поперечник ЖП; Н - длинник ЖП. При этом оценивали следующие параметры: исходный объем ЖП; длительность фазы сокращения ЖП; степень максимального сокращения его от исходного уровня; скорость опорожнения ЖП (отношение максимального сокращения к длительности фазы сокращения). АГБСГ выполнялась на гамма-камере MB-9200 с процессором Super Segams после внутривенного введения гепатотропного радиофармпрепарата (РФП) Бромезида-Тс99 общей активностью 185-370 МБк, с использованием желчегонной стимуляции, состоящей из 2 сырых яичных желтков. При анализе гепатограмм оценивалась депонирующая функция ЖП по времени максимального накопления РФП в ЖП (Тmax ЖП), моторно-эвакуаторная функция желчного пузыря по времени полувыведения РФП из ЖП (Т¹/2 ЖП) и латентному времени желчегонного завтрака.

Проведено микроскопическое и биохимическое исследование желчи, полученной при многофракционном дуоденальном зондировании. В порциях (В) и (С» желчи определялась суммарная концентрация желчных кислот (ЖКВ, ЖКС) и холестерина (ХСВ, ХСС) [14], вычислялся холато-холестериновый коэффициент (ХХKВ, ХХКС), являющийся индексом литогенности желчи. В периферической крови исследовали уровень гастроинтестинального гормона гастрина методом двухстадийного (сэндвич) иммуноферментного анализа.

В контрольную группу вошли 30 практически здоровых лиц в возрасте от 20 до 25 лет.

Статистическую обработку полученных результатов проводили с использованием стандартного пакета в редакторе Microsoft Office Excel версии 2010. Аанные представленные в виде средних величин (М) с определением их ошибок $( \pm \mathrm{m})$ сравнивали методом корреляционного анализа с вычислением коэффициента корреляции (r) по формуле Пирсона. Аостоверность оценивалась по критерию Стьюдента при нормальном распределении выборки.

\section{Результаты и обсуждение}

Абдоминальные боли беспокоили всех пациентов, в 84\% случаев боль локализовалась в правом подреберье, в 16\% - в эпигастрии. Постоянная, тупая, усиливающаяся после еды (главным образом, после жирной пищи) боль, сопровождающаяся чувством давления, распирания, с иррадиацией в спину, под правую лопатку, в правое плечо наблюдалась у $68 \%$ пациентов, 32\% пациентов отмечали боль кратковременную, коликоподобную, возникающую при погрешностях в диете. Кроме того, у 76\% пациентов при сборе анамнеза выявлены симптомы билиарной диспепсии, среди которых преобладали отрыжка, тошнота, горечь во рту.

При объективном обследовании 78\% больных были повышенного питания, у 56\% пациентов выявлялась обложенность языка желтым или серо-желтым налетом, отпечатки зубов по краям, у 83\% - определялась пальпаторная болезненность с локализацией в правом подреберье и положительные желчно-пузырные симптомы. При УЗИ уплотнение и утолщение стенки ЖП наблюдалось у $62 \%$ пациентов, деформация ЖП у $30 \%$ пациентов, наличие билиарного сладжа (микролиты, замазкообразная желчь) - у 78\% пациентов.

На основании результатов холецистометрии пациенты были разделены на три подгруппы: 1-я - с дисфункцией ЖП по гипокинетическому типу, 2-я с нормальной сократительной активностью ЖП, 3-я с - с дисфункцией ЖП по гиперкинетическому типу. Подгруппы были уравновешены по полу и возрасту. В 1-ю подгруппу вошли 49 женщин и 40 мужчин, средний возраст составил $51 \pm 2$ лет, во 2-ю подгруппу - 36 женщин и 39 мужчин, средний возраст составил $44 \pm 4$ лет, в 3-ю подгруппу - 32 женщины и 34 мужчины, средний возраст составил $49 \pm 4$ лет. Судя по данным пабл.1, достоверных различий между исходным объемом ЖП при различных вариантах моторики не отмечено.

Как показано на рис. 1, у больных с дисфункцией ЖП по гиперкинетическому типу после пробного завтрака увеличивается скорость опорожнения ЖП,

Таблица 1. Аанные исследования мопорики желчного пузыря при различных функциональных расспройспвах Table 1. Data of the study motility of the gallbladder with various functional disorders

\begin{tabular}{|c|c|c|c|c|}
\hline $\begin{array}{c}\text { Показатель/ } \\
\text { Parameter }\end{array}$ & $\begin{array}{c}\text { Контроль/ } \\
\text { control } \\
(\mathrm{n}=\mathbf{3 0})\end{array}$ & $\begin{array}{c}1 \text { подгруппа/ } \\
1 \text { subgroup } \\
(\mathbf{n}=\mathbf{8 9})\end{array}$ & $\begin{array}{c}2 \text { подгруппа/ } \\
2 \text { subgroup } \\
\text { (n=66) }\end{array}$ & $\begin{array}{c}3 \text { подгруппа/ } \\
3 \text { subgroup } \\
(\mathrm{n}=75)\end{array}$ \\
\hline $\begin{array}{l}\text { Алительность фазы сокращения, мин/ } \\
\text { The duration of the phases of reduction, min. }\end{array}$ & $45,64+4,2$ & $52,41+4,4$ * & $46,62+3,4^{*}$ & $39,25+2,5 *$ \\
\hline $\begin{array}{l}\text { Степень максимального сокращения, \% / } \\
\text { The degree of maximum contraction, \% }\end{array}$ & $46,43+3,8$ & $29,24+2,7 *$ & $47,01+5,8 *$ & $63,63+6,2 *$ \\
\hline $\begin{array}{l}\text { Скорость опорожнения ЖП, \%/мин/ } \\
\text { The rate of emptying of the gallbladder, \%/min }\end{array}$ & $1,02+0,4$ & $0,85+0,04 *$ & $1,03+0,09 *$ & $1,87+0,2^{*}$ \\
\hline $\begin{array}{l}\text { Исходный объем ЖП, см }{ }^{3} / \\
\text { The initial volume of the gallbladder, } \mathrm{cm}^{3}\end{array}$ & $16,75+1,8$ & $17,1+2,0^{*}$ & $16,85+2,4^{*}$ & $16,23+2,1^{*}$ \\
\hline
\end{tabular}

Примечание: * - $\mathrm{P}<0,05$ по сравнению с контролем/Note: * compared with the control 


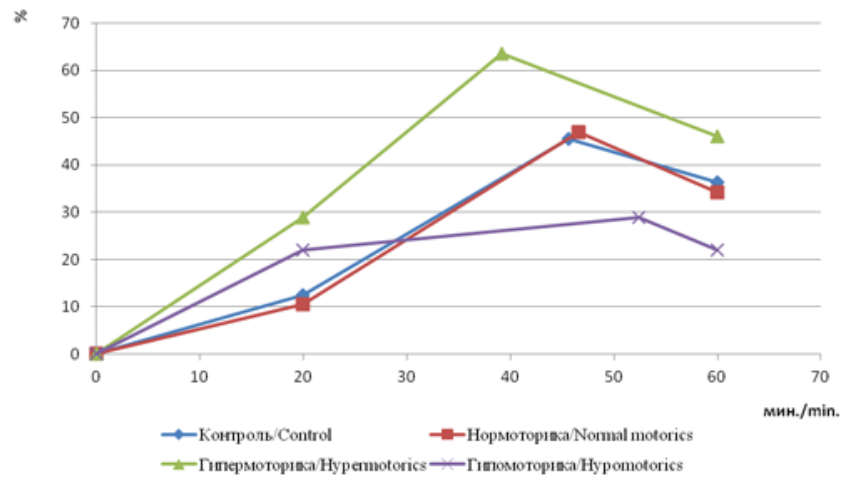

Рисунок1. Показапели сокрапипельной функции ЖП после использования пробного завтрака

Figure 1. The parameters of the contractile function of the LR after using the trial breakfast

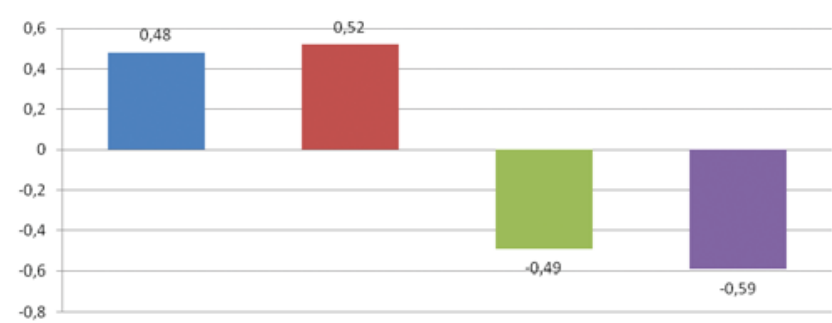

=Скорость опорожнения ЖП/The rate of emptying of the gallbladder - Степень макс. сокращения жп/The degree of maximum contraction

= Латентное время желчегонного завтрака/Latent time of cholagogue breakfast

- Время полувыведения радиофармпрепарата из ЖП/Нalf-life of the radiopharmaceutical from gallbladder

Рисунок 2. Аанные корреляционного анализа между уровнем гасприна и показапелями функционального соспояния ЖП.

Figure 2. The data of correlation analysis between the level of gastrin and indicators of the functional state of the gallbladder. причем не только за счет увеличения степени максимального сокращения, но и за счет уменьшения длительности фазы сокращения. При дисфункции ЖП по гипокинетическому типу уменьшение скорости опорожнения его было связано снижением степени максимального сокращения и увеличением длительности фазы сокращения.

Однонаправленные изменения показателей двигательной активности ЖП по данным холецистометрии и АГБСГ (табл. 2) убеждают в их информативности и равноценности в ранней диагностике ЖКБ.

Базальный уровень гастрина у обследованных пациентов был снижен (табл. 3), причем в большей степени - при дисфункции ЖП по гипокинетическому типу. На сегодня существуют противоречивые данные об участии гастрина в процессах холереза и холекинеза. Аоказано, что в мышечной стенке ЖП содержатся рецепторы гастрина. Гастрин оказывает стимулирующее действие на сокращение ЖП и расслабляющее действие - на сфинктер Одди, вызывая понижение давления в системе желчевыводящих путей [15]. Одни авторы доказывают усиление гастрином дуоденальной инкреции холецистокинина [16], оказывающего стимулирующее влияние на сократительную способность ЖП. Аругие отмечают улучшение печеночного кровотока под влиянием гастрина, следствием чего являются положительные сдвиги со стороны метаболических процессов в печени и усиление холереза [17].

Результаты проведенного корреляционного анализа (рис. 2) свидетельствующие о существовании зависимости между уровнем гастрина и функциональным состоянием ЖП, являются доказательством того, что гипогастринемия приводит к уменьшению скорости

Таблица 2. Корреляционный анализ показапелей моторно-эвакуаторной функции ЖП при различных меподах их исследования

Table 2. Correlation analysis of indicators of the motor-evacuator function of the HP in various methods of their investigation

\begin{tabular}{|c|c|c|}
\hline Показатель/Parameter & $\begin{array}{c}\text { Время полувыведения РФП } \\
\text { из ЖП на ДГБСГ/ } \\
\text { Half-life of radiopharmaceuti- } \\
\text { cal from gallbladder on dynam- } \\
\text { ic hepatobiliary scintigraphy }\end{array}$ & $\begin{array}{c}\text { Латентное время желчегон- } \\
\text { ного завтрака на ДГБСГ/ } \\
\text { Latent time of cholagogue } \\
\text { breakfast on dynamic hepatobi- } \\
\text { liary scintigraphy }\end{array}$ \\
\hline $\begin{array}{l}\text { Алительность фазы сокращения на холецистометрии/ } \\
\text { Duration of the contraction phase on cholecystometry }\end{array}$ & $r=0,49$ & $\mathrm{r}=0,36$ \\
\hline $\begin{array}{l}\text { Скорость опорожнения ЖП на холецистометрии/ } \\
\text { The rate of emptying of the gallbladder on cholecystometry }\end{array}$ & $r=-0,70$ & $r=-0,60$ \\
\hline
\end{tabular}

Таблица 3. Базальный уровень гастрина крови при различных функциональных расстройствах ЖП Table 3. Basal levels of blood gastrin in different functional disorders of the gallbladder

\begin{tabular}{|c|c|c|c|c|}
\hline $\begin{array}{c}\text { Показатель/ } \\
\text { Parameter }\end{array}$ & $\begin{array}{c}\text { Контроль/ } \\
\text { control } \\
(\mathrm{n}=\mathbf{3 0})\end{array}$ & $\begin{array}{c}1 \text { подгруппа/ } \\
1 \text { subgroup } \\
\text { (n=89) }\end{array}$ & $\begin{array}{c}2 \text { подгруппа/ } \\
2 \text { subgroup } \\
\text { (n=66) }\end{array}$ & $\begin{array}{c}3 \text { подгруппа } \\
3 \text { subgroup } \\
\text { (n=75) }\end{array}$ \\
\hline Гастрин (пг/мл)/Gastrin ( & $66,14+3,32$ & $24,45+2,91^{*}$ & $27,06+3,02 *$ & $28,44+2,13^{*}$ \\
\hline
\end{tabular}

Примечание: * $-\mathrm{P}<0,05$ по сравнению с контролем/Note: compared with the control 
Таблица 4. Биохимические показатели желчи при различных нарушениях моторики ЖП

Table 4. Biochemical parameters of bile in various motility disorders of the gallbladder

\begin{tabular}{|c|c|c|c|c|}
\hline $\begin{array}{c}\text { Показатель/ } \\
\text { Parameter }\end{array}$ & $\begin{array}{c}\text { Контроль/ } \\
\text { control } \\
(\mathbf{n}=\mathbf{3 0})\end{array}$ & $\begin{array}{c}1 \text { подгруппа/ } \\
1 \text { subgroup } \\
(\mathrm{n}=\mathbf{8 9})\end{array}$ & $\begin{array}{c}2 \text { подгруппа/ } \\
2 \text { subgroup } \\
(\mathrm{n}=66)\end{array}$ & $\begin{array}{c}3 \text { подгруппа/ } \\
3 \text { subgroup } \\
(\mathrm{n}=75)\end{array}$ \\
\hline $\begin{array}{l}\text { ХC (ммоль/л)/Cholesterol (mmol/l) } \\
\text { Порция «В») / Portion «B» } \\
\text { Порция «С») / Portion «C») }\end{array}$ & $\begin{array}{l}7,53+2,14 \\
3,45+0,9\end{array}$ & $\begin{array}{l}30,14+4,9^{*} \\
21,28+3,6^{*}\end{array}$ & $\begin{array}{c}19,91+4,6^{*} \\
10,78+2,1\end{array}$ & $\begin{array}{l}26,73+3,8^{*} \\
15,84+3,4^{*}\end{array}$ \\
\hline $\begin{array}{l}\text { ЖК (ммоль/л)/Bile acids (mmol/l) } \\
\text { Порция (B») / Portion “В») } \\
\text { Порция “С») / Portion “C») }\end{array}$ & $\begin{array}{c}53,52+5,4 \\
19,14+2,7\end{array}$ & $\begin{array}{l}24,25+4,4 \\
14,76+2,5^{*}\end{array}$ & $\begin{array}{l}49,14+4,8^{*} \\
17,37+1,4^{*}\end{array}$ & $\begin{array}{l}37,24+3,1^{*} \\
18,44+2,7^{*}\end{array}$ \\
\hline $\begin{array}{l}\text { XXК (еа }) \text { /cholate-cholesterol ratio (UOM) } \\
\text { Порция «B»/ Portion «B» } \\
\text { Порция «C»/ Portion «C» }\end{array}$ & $\begin{array}{l}9,53+1,1 \\
6,37+1,7\end{array}$ & $\begin{array}{l}0,84+0,04^{*} \\
0,69+0,01^{*}\end{array}$ & $\begin{array}{l}2,46+0,6 \\
1,61+0,4^{*}\end{array}$ & $\begin{array}{c}1,33+0,09 \\
1,16+0,09^{*}\end{array}$ \\
\hline
\end{tabular}

Примечание: * - P<0,05 по сравнению с контролем/Note: compared with the control

Таблица 5. Данные корреляционного анализа между уровнем гастрина и показапелями биохимических исследований желчи

Table 5. The data of correlation analysis between the level of gastrin and biochemical properties of bile

\begin{tabular}{|c|c|c|c|c|c|c|}
\hline $\begin{array}{c}\text { Показатель/ } \\
\text { Parameter }\end{array}$ & $\begin{array}{c}\text { ХСв / } \\
\text { Cholesterol B }\end{array}$ & $\begin{array}{c}\text { XCc / } \\
\text { Cholesterol C }\end{array}$ & $\begin{array}{c}\text { ЖКв / } \\
\text { Bile acids B }\end{array}$ & $\begin{array}{c}\text { ЖKC / } \\
\text { Bile acids C }\end{array}$ & $\begin{array}{c}\text { XXKB / } \\
\text { cholate-cho- } \\
\text { lesterol ratio B }\end{array}$ & $\begin{array}{c}\text { XXKc/ } \\
\text { cholate-cho- } \\
\text { lesterol ratio C }\end{array}$ \\
\hline Гастрин /Gastrin & $r=-0,31$ & $r=-0,31$ & $\mathrm{r}=0,47$ & $\mathrm{r}=0,35$ & $\mathrm{r}=0,38$ & $\mathrm{r}=0,31$ \\
\hline
\end{tabular}

опорожнения ЖП, степени максимального сокращения ЖП при холецистометрии, а также к увеличению времени полувыведения РФП из ЖП и латентного времени желчегонного завтрака при АГБСГ.

У 75,4\% пациентов при микроскопии желчи найдены кристаллы холестерина и билирубината кальция, характерные для первой, докаменной стадии ЖКБ. Оценка биохимического состава желчи проводилась в зависимости от вида моторно-эвакуаторной функции желчного пузыря. Как показывают данные табл. 4, у обследуемых больных в желчи содержание $\mathrm{XC}$, в сравнении с контролем, было повышено как в порции (В), так и в порции (С). Напротив, уровень ЖК, в сравнении с контролем, был снижен и в порции (В», и в порции (С». Выявлено значительное снижение XXК в обеих порциях желчи в сравнении с контрольной группой. Наибольшая степень литогенности желчи наблюдалась при дисфункциях ЖП по гипокинетическому типу.

По данным таблицы 5, изменения биохимического состава желчи находятся в прямой зависимости от уровня гастрина. При пониженном уровне гастрина наблюдается увеличение содержания ХС и уменьшение ЖК в порциях (В) и (С») желчи. Выявлена положительная корреляция между уровнем гастрина и XXK, то есть при снижении содержания гастрина уменьшается ХХК.

Таким образом, гипогастринемия, коррелирующая с нарушением функционального состояния ЖП и изменененным биохимическим составом желчи, указывает на существенную роль гастрина в желчном камнеобразовании.

\section{Заключение}

У $72 \%$ пациентов с заболеваниями гепатобилиарной системы выявляются нарушения моторно-эвакуаторной функции ЖП. Аисфункция ЖП по гипокинетическому типу, является прогностически более неблагоприятной в отношении возможного желчного камнеобразования. Исследования показателей моторной функции ЖП и биохимических свойств желчи с одной стороны и уровня гастроинтестинального гормона гастрина с другой позволили показать важную роль гипогастринемии в формировании литогенной желчи путем подавления опорожнения ЖП.

\section{Конфликт интересов/Conflictum of interest}

Авторы заявляют, что данная работа, её тема, предмет и содержание не затрагивают конкурирующих интересов/The authors state that this work, its theme, subject and content do not affect competing interests.

\section{Список литературы / References:}

1. Вахрушев Я.М., Хохлачева Н.А., Горбунов А.Ю. Желчнокаменная болезнь (эпидемиология, ранняя диагностика, диспансеризация). Ижевск: Типография УДГУ, 2014; 132 с.

Vakhrushev Ya.M., Khokhlacheva N.A, Gorbunov A.Yu. Gallstone disease (epidemiology, early diagnosis, clinical examination). Izhevsk: Printing house of UdSU, 2014; 132 p. [in Russian].

2. Вахрушев Я.М., Хохлачева Н.А. Опыт консервативного лечения пациентов с желчнокаменной болезнью. Ижевск: Типография Удгу, 2011; 144c

Vakhrushev Ya.M., Khokhacheva N.A. Experience in conservative treatment of patients with cholelithiasis. Izhevsk: Printing house of UdSU, 2011; 144p. [in Russian].

3. Acalovshi M. Cholesterol gallstones: from epidemiology to preventive Postgrad. Med. J. 2007; 77: 221-229. 
4. Ильченко А.А. Классификация желчнокаменной болезни. Экспериментальная и клиническая гастроэнтерология. 2002; 1: 131. Ilchenko A.A Classification of cholelithiasis . Experimental and clinical gastroenterology. 2002; 1: 131 [in Russian].

5. Ильченко А.А. Болезни желчного пузыря и желчных путей. Руководство для врачей. Москва: МИА, 2011; 880 с.

Ilchenko A.A. Diseases of the gallbladder and biliary tract. A guide for doctors. Moscow: MIA, 2011; 880 p. [in Russian].

6. Лукашевич А.П. Прогнозирование развития желчнокаменной болезни у пациентов с патологией гепатобилиарной системы. Практическая медицина. 2015; 7(92): 115-119.

Lukashevich A.P. Predicting the development of cholelithiasis in patients with pathology of the hepatobiliary system. Practical medicine. 2015; 7 (92): 115-119 [in Russian]

7. Marshall, H. U. Gallstone disase . J. Int. Med. 2007; 261: 529-542.

8. Григорьева И.Н. Новый взгляд на ЖКБ. Сибирский вестник гастроэнтерологии и гепатологии. 2006; 20: 26-27. Grigoryeva I.N. A new look at the Cholelithias. Siberian Journal of Gastroenterology and Hepatology. 2006; 20: 26-27 [in Russian].

9. Максимов В.А., Чернышев А.Л., Тарасов К.М., Неронов В.А. Билиарная недостаточность. Москва: Адамантъ, 2008; 232 с. Maksimov VA, Chernyshev A.L., Tarasov K.M., Neronov V.A. Biliary insufficiency. Moscow: Adamant, 2008; 232 p. [in Russian].

10. Хохлачева Н.А., Сучкова Е.В., Вахрушев Я.М. Пути повышения эффективности диспансеризации больных ранней стадией желчнокаменной болезни. Экспериментальная и клиническая гастроэнтерология. 2013; 4: 15-20.

Khokhlacheva N.A., Suchkova E.V., Vakhrushev Ya.M. Ways to improve the effectiveness of clinical examination of patients with early stage of cholelithiasis. Experimental and clinical gastroenterology. 2013; 4: 15-20 [in Russian].
11. Degen $\mathrm{L}$. Role of free fatty acids in regulating gastric emptying and gallbladder contraction. Digestion. 2006; 74 (3-4): 131-139.

12. Xu D. Control of gallbladder contractions by cholecystokinin through cholecystokinin-A receptors on gallbladder interstitial cells of Cajal. World J. Gastroenterol. 2008; 14 (18): 2882-2887.

13. Вахрушев Я.М., Трусов В.В., Виноградов Н.А. Печень и гормоны. Ижевск, 1992: 112 с.

Vakhrushev Ya.M., Trusov V.V., Vinogradov N.A. Liver and hormones. Izhevsk, 1992: 112 p. [in Russian].

14. Мирошниченко В.П., Громашевская Л.Л., Касаткина М.Г., Козачек Г.А. Определение содержания желчных кислот и холестерина в желчи. Лаб.дело. 1978; 3: 149-153.

Miroshnichenko V.P., Gromashevskaya L.L., Kasatkina M.G., Kozachek G..A. Determination of the content of bile acids and cholesterol in bile. Lab. Business. 1978; 3: 149-153 [in Russian].

15. Уголев А.М., Радбиль О.С. Гормоны пищеварительной системы. Москва, 1995: 200 с.

Ugolev A.M., Radbil O.S. Hormones of the digestive system. .Moscow, 1995: 200 p. [in Russian].

16. Fischler B. Cholestatic liver disease in adults may be due to an inherited defect in bile acid biosynthesis. J. Intern. Med. 2007; 262: 254-262.

17. Иванченкова Р.А. Хронические заболевания желчевыводящих путей. Москва: Атмосфера, 2006; 415 с.

Ivanchenkova R.A. Chronic diseases of bile ducts. Moscow: Atmosphere, 2006; 415 p. [in Russian].

Статья получена/Article received 30.10.2017 г. Принята к публикации/ Adopted for publication 15.12.2017 г.

\section{ГЕПАТИТ С КАК ФАКТОР РИСКА РАЗВИТИЯ ЖЕЛЧЕКАМЕННОЙ БОЛЕЗНИ}

Введение: желчекаменная болезнь и ее осложнения в настоящее время является самым частым заболеванием гепатобилиарного тракта. Результаты нескольких эпидемиологических исследований позволяют предположить что у пациентов с вирусным гепатитом С риск развития желчекаменной болезни выше чем в популяции в целом. Однако однозначных результатов получено не было. Данный метанализ направлен на аккумуляцию результатов различных исследований.

Методы: использовались базы данных MEDLINE и EMBASE, период исследования - май 2016 года. Были использованы исследования, в которых оценивались относительный риск, отношение шансов и отношение рисков развития желчекаменной болезни у пациентов с вирусным гепатитом С и здоровых. Оценивались объединенное отношение шансов и 95\% доверительный интервал.

Результаты: критериям мета-анализа соответствовали 11 исследований. Объединенное отношение шансов развития желчекаменной болезни у пациентов, инфицированных вирусом гепатита С по сравнению со здоровыми составило 1,83 (95\% ДИ, 1,35-2,48, $1^{2}=89 \%$ ). Анализ по подгруппам продемонстрировал высокий риск как для женщин (объединенное отношение шансов 3,00, 95\% ДИ, 2,16-4,17), так и для мужчин (объединенное отношение шансов 2,07, 95\% ДИ, 1,14-3,76).

Заключение: результаты мета-анализа демонстрируют, что в популяции пациентов с вирусным гепатитом С риск развития желчекаменной болезни значительно выше, чем в целом в популяции.

Wijarnpreecha K., Thongprayoon C., Panjawatanan P., Lekuthai N., Ungprasert P. Hepatitis $C$ virus infection and risk of gallstones: A meta-analysis. J. Evid. Based. Med. 2017 Nov; 10(4): 263-270. doi: 10.1111/jebm.12277. 